\title{
Estrategias para reactivar espacios postindustriales. Caso de estudio: Sector Quitumbe.
}

\author{
Javier Benavides ${ }^{1}$, Daysi Portalanza Bonilla ${ }^{2}$, \\ Darío Silva Granizo ${ }^{3}$, Alejandro Samaniego Wagner ${ }^{4}$
}

Facultad de Arquitectura, Diseño y Artes, Pontificia Universidad Católica del Ecuador, Quito, Ecuador E-mail: 1jebenavides@puce.edu.ec, ${ }^{2}$ dportalanza95@gmail.com, 3arq.dsil@gmail.com, ${ }^{4}$ asamaniegow@gmail.com

\begin{abstract}
Resumen. La consecuencia del desarrollo industrial de una urbe es la implementación de servicios y medios de transporte que generan cambios morfológicos dentro de la ciudad. Muchos de ellos no incluyen un planeamiento urbano, por lo que el crecimiento se da de manera desordenada y pocas veces cumplen con los requisitos de calidad de vida urbana. A lo largo de la historia de Quito, capital del Ecuador, un factor que determinó a la actividad industrial fue la llegada del ferrocarril, ya que su eje provocó el emplazamiento de los polígonos fabriles y esto, a su vez, conllevó a la disgregación de la ciudad. Dicho crecimiento urbano anuló el dinamismo de actividades, contradiciendo los principios de una ciudad habitable. Se analizó el caso especifico del sector Quitumbe puesto que afronta la problemática urbana planteada en el presente ensayo. Los resultados del análisis brindarán estrategias y posturas de diseño que logren cohesionar los fragmentos dispersos de la ciudad, suturando y articulando estos grandes "guetos industriales" dentro de la urbe. La industria es parte fundamental para el desarrollo económico de la ciudad, por lo tanto, el problema se presenta como solución para una coexistencia sostenible entre los ejes de movilidad, hábitat urbano e industrial. Las estrategias afrontarán la reactivación de zonas postindustriales en un ámbito general, a la vez de dar lineamientos a ser aplicados en el caso de estudio.
\end{abstract}

Palabras clave: zonas postindustriales, reactivación urbana, poligonos industriales, crecimiento poblacional, Quitumbe, paisaje industrial..

\section{Introducción}

Las transformaciones urbanas tanto morfológicas comotipológicassonconsecuencia del cambio de modelo económico. El cambio radical que sufre la sociedad industrializada a partir de la segunda mitad del siglo XX, y sus consecuencias que son más evidentes en los años 70, incide directamente en las urbes latinoamericanas. Estas pueden definirse como grandes islas que han sido absorbidas por el crecimiento de la urbe. En el caso de Quito, los barrios obreros se van insertando en las periferias laterales del eje férreo, puesto que los polígonos industriales articulados al eje en desuso se han convertido en elementos ajenos a la ciudad. Hoy en día dichos «archipiélagos» o «islas» ajenas a la lógica morfológica de la urbe, como señala Careri (2009), son "amnesias urbanas donde no existe nada y se busca que surja algo de ello. (...) Lugares que no sólo buscan ser llenados de cosas, sino que hay que asignarles valores y significados." El caso de estudio Quitumbe involucra ejes viales articulados a polígonos fabriles, estos con el tiempo se han vuelto obsoletos, provocando baja densidad en el eje central. En los próximos años las excentricidades quedarán densificadas, mientras que su centralidad articulada al eje férreo quedará obsoleta convirtiéndose en una 
serie de elementos postindustriales dejando grandes anomalías urbanas en su recorrido. Por lo cual, la postura sería "reinsertar dichas amnesias a la ciudad".

\section{Reseña histórica}

Quito fue fundada en 1534, su forma de distribuir la ciudad tenía como principios: separar, diferenciar y ordenar en ámbitos sociales y espaciales. Así el centro de la ciudad albergó a la clase alta y destinó a las periferias a los llamados barrios de indios, las zonas agropecuarias y artesanías textiles. Las primeras industrias aparecen en los años de 1900 y fueron ubicadas en el extremo sur de la ciudad, desencadenando la formación de barrios obreros en las cercanías de los polígonos fabriles.

El ferrocarril marcó un importante crecimiento para la ciudad, porque gracias a este se pudo movilizar materiales de construcción de manera más rápida, lo que aceleró el proceso de urbanización, tal es así, que Quito deja de crecer de manera radial y se proyecta longitudinalmente ${ }^{1}$, en esta nueva morfología de la ciudad las clases privilegiadas se ubican al norte mientras que las clases desposeídas son ubicadas al sur junto a la industria, bodegas y galpones que se implantan sin orden alguno. (Achig, 1983)

El ferrocarril fue de tal importancia que, en 1942, el primer plan urbano de la ciudad, desarrollado por el arquitecto Jones Odriozola, considera que al encontrarse la estación de Chimbacalle en el extremo sur de la ciudad el sector debía destinarse a transporte de carga, industria y vivienda obrera, dando prioridad a la densificación sin desarrollo de calidad de vida por el déficit de áreas destinadas a servicios y equipamientos. Entre los años de 1973 y 1993 aumentó el flujo migratorio de campesinado hacia la capital. A partir de 1983 el sector de Quitumbe llega a ser parte urbana de Quito, en él se implantan las primeras «islas» industriales y junto a ellas amanzanamientos de menor tamaño de edificaciones residenciales para la clase trabajadora.

El plan ordenador Quito 2000 - 2020 menciona la aparición de diferentes clases de residencias, mientras al norte de la ciudad se proponía mixticidad, el sur se mantenía rígido a introducir variedad de usos. Además, cabe mencionar que el ferrocarril, uno de los factores que dotó de la característica industrial a la zona, dejó de funcionar de manera pública y se destinó a un uso turístico. La propuesta urbana 2012-2022 muestra la idea de centralidades en el distrito metropolitano, las cuales se concentran el centro norte, dejando suelto el planteamiento de servicios y equipamientos e ignorando la existencia del ferrocarril.

En síntesis, los planeamientos urbanos del siglo XX se han esforzado por densificar el sur de la ciudad mas no han provisto de variedad de usos más que la residencia y la industria, creando un déficit de servicios y equipamientos, esto repercute en la calidad de vida que se le da a buena parte de la población de la ciudad. Por tal motivo el estudio se centra en el sector Quitumbe, por su carácter de industria y residencia obrera que colinda con el eje férreo.

\section{Los polígonos fabriles y el eje férreo.}

Según la ordenanza 0127 del distrito metropolitano de Quito aprobada el 18 de julio del 2016, las edificaciones industriales están destinadas a la transformación de materias primas o semielaboradas y actividades afines, estas están clasificadas según su impacto en I1 bajo, I 2 medio, I 3 alto e I4 peligroso.

En el año 2012, la alcaldía de la ciudad para enfrentar el hecho de que los grandes polígonos industriales quedaron rodeados por el crecimiento de la ciudad y esta relación entre urbe e industria concluía en caos para ambos frentes, deciden realizar un estudio de mercado para nominar un nuevo parque industrial fuera de la ciudad; los resultados del estudio nombran a las áreas de Itulchachi, Calacalí y Turubamba como factibles áreas para el traslado de la industria (PwC 2012), al momento del presente estudio, año 2018, efectivamente dichos sectores están siendo ocupados por industria en especial de alto y peligroso impacto, mas existen todavía construcciones fabriles que han quedado rezagadas o han sido renuentes al cambio de sector. Uno de los sectores urbanos donde se puede evidenciar esto es Quitumbe. El fenómeno de crecimiento encerró de igual manera al eje férreo, el cual cruza de forma 


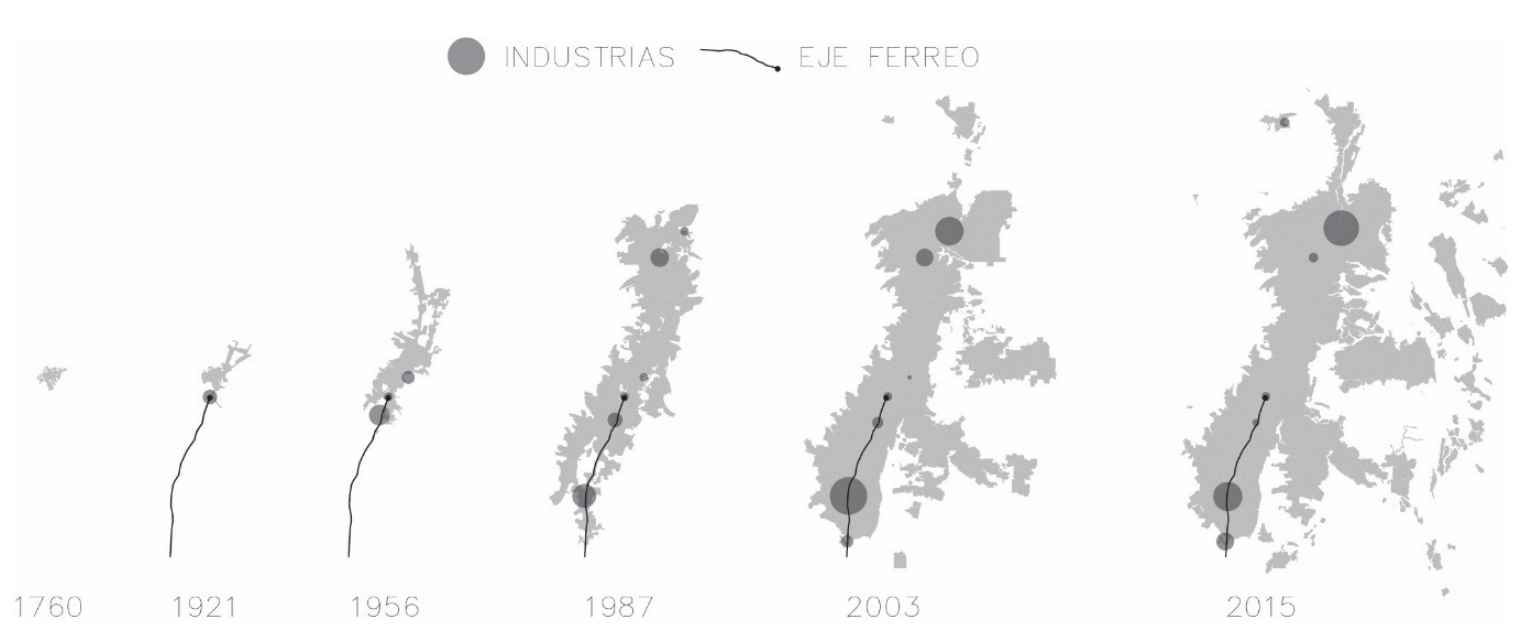

Fig. 1. La industria en Quito. (Fuente: D. Silva, 2019)

longitudinal al sector.

Por el avance en el ámbito de movilidad, en 1997 la industria dejó de utilizar al ferrocarril como un medio de transporte para su abastecimiento. Actualmente el Estado ha buscado mantener activa la línea férrea con diferentes programas turísticos, cuyos horarios y recorridos son ocasionales, dejando deshabitada la mayor parte del tiempo su trayecto. La ciudad reacciona con sus frentes de diferentes maneras hacia el riel, existen intervalos donde se dejan áreas libres a cada lado, tramos donde es parte de calles y avenidas y momentos donde casas e industrias encasillan y dan la espalda al eje.

De esta manera el sector se ve fraccionado por dos factores, las grandes áreas de industria que deja amnesias urbanas sin una adecuada convivencia con la urbe y el eje férreo, cuyas franjas son deshabitadas y divide al sector.

\section{Análisis de caso}

\section{Ocupación y densidad poblacional en el sector}

La Municipalidad del Distrito desarrolló el plan Quito 2040 como manual de desarrollo de la ciudad a futuro, en ella se plantea a la densidad bruta como la relación entre la población que se asienta en un territorio y su superficie total. Quito tiene una densidad bruta total de 54.5 hab/ha, en la visión 2040 se considera una densidad óptima de 120 hab/ha, lo que implica que la ciudad está en capacidad de aumentar su población dentro de la mancha urbana actual.
(2018).

El sector de estudio está en medio de dos parroquias: Quitumbe con una densidad bruta de 38.9 hab/ha y La Argelia que tiene una densidad bruta de 76.4 hab/ha. Para el análisis del sector, la investigación lo dividió en tres franjas transversales.

La zona 1 tiene una densidad de $220 \mathrm{hab} /$ ha y una ocupación de suelo en planta baja de $27.90 \%$, la zona 2 tiene una densidad poblacional de $124 \mathrm{hab} / \mathrm{ha}$ y una ocupación de suelo de $13.90 \%$ y la zona 3 maneja una densidad de $153 \mathrm{hab} / \mathrm{ha}$ y tiene una ocupación del suelo de 19.98\%. Dichos datos demuestran que a zona 1 al estar más construida alberga más población, la zona 2 congrega más polígonos fabriles y equipamientos por lo que su ocupación es la menor de todas al igual que su densidad poblacional.

\section{Trama urbana}

Una de las principales características del sector Quitumbe es su trama urbana, en ella se muestran manzanas de $1386 \mathrm{~m} 2$ hasta 140 $141 \mathrm{~m} 2$, en las de mayor tamaño se implanta la industria. La zona 1 cuenta con 275.66 ha de las cuales 45.61 ha son destinadas a industria lo que representa un $16.54 \%$. La zona 2 cuenta con 275.15 ha de las cuales 32.02 ha son industriales lo cual se traduce en un $11.63 \%$; finalmente la zona 3 tiene 259.84 ha de las cuales 26.49 ha son destinadas a industria y esto representa un 10.19\%. Concluyendo en que la industria constituye grandes vacíos 
provocando amnesias urbanas sin diálogo con su entorno residencial.

La urbanización del sector se determinó debido a las industrias, es decir que lotizaciones irregulares dieron los lineamientos para el desarrollo de los barrios residenciales, a medida que los barrios crecían iban conformando diferentes tipos de tramas, las cuales no siempre mantenían continuidad en sus ejes viales, orientación de implantación y tipología de construcción. Este fenómeno de crecimiento diversificado condiciona un sector fraccionado desde su misma trama urbana.

Otro factor que conforma parte de la trama son las áreas verdes, las cuales fueron construidas a partir de espacios residuales del entramado urbano. Son pocas las áreas que fueron planificadas bajo el objetivo de conformar espacio público para la población, y muchas de ellas apenas se constituyeron en los últimos años. El área verde en la zona 1 tiene $3.61 \mathrm{~m} 2 / \mathrm{hab}$, en la zona 2 posee $10.50 \mathrm{~m} 2 / \mathrm{hab}$ y la zona 3 asume $1.20 \mathrm{~m} 2 / \mathrm{hab}$. La organización mundial de la salud recomienda un área verde mínima de $9 \mathrm{~m} 2$ y una óptima de $15 \mathrm{~m} 2$ por habitante. Por lo que el sector en su zona más crítica tiene un déficit de $7.80 \mathrm{~m} 2$ de área verde.

\section{Uso de suelo}

Un elemento importante para determinar el abastecimiento de un sector, son los equipamientos que en él se implantan, la investigación pudo identificar un total de 115; para ello se consideró como equipamientos lotes y construcciones dedicados a temas de: educación, salud, comercial, servicios públicos y cultura.

Según Salvador Rueda la mixtura de usos permite instaurar una red asociativa que permite crear ciudades compactas (1997). El sector está medianamente abastecido, mas no fue pensado como tal, ya que a partir de los años 2000 grandes equipamientos se instauraron en el sector. La zona 1 tiene la mayor concentración de equipamientos con un total de 64 distribuidos en $725495 \mathrm{~m} 2$. La zona 2 le sigue en número de equipamientos, con un total de 35, abarcando $520106 \mathrm{~m} 2$. Finalmente, la zona 3 cuenta con 16 servicios ocupando $202564 \mathrm{~m} 2$. Se puede evidenciar que la zona 1 al estar más cercana al centro de la ciudad cuenta con mayor número de equipamientos, lo que genera más intercambios sociales (Rueda 1997); mientras que en la zona 3 destina $7.80 \%$ a servicios, mientras que alberga $10.19 \%$ de industria, demostrando que los barrios concebidos como obreros, no tuvieron una planificación dirigida a la mixticidad de usos desencadenando en barrios dormitorio. Este hecho contradice la idea sobre que los equipamientos y servicios de calidad constituye una de las piezas fundamentales en los procesos de recuperación de los barrios vulnerables. (Gutiérrez 2013)

El análisis del sector demuestra que: las
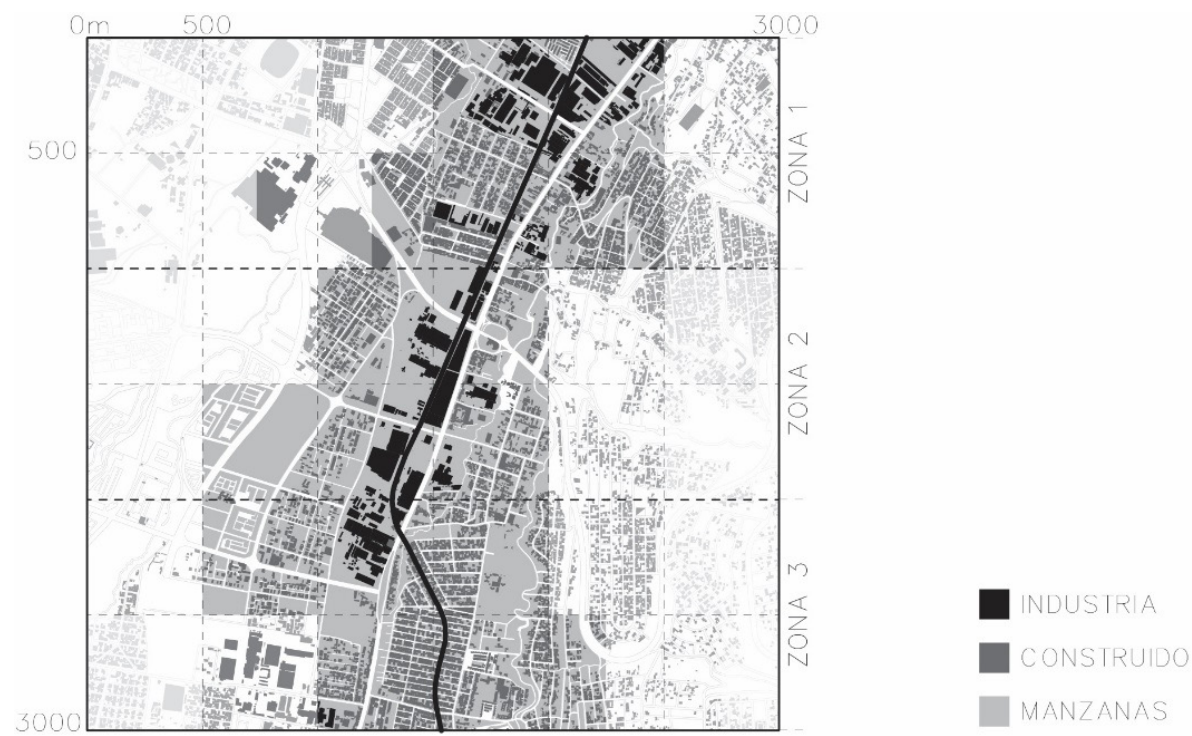

Fig. 2. La industria en el sector. (Fuente: D. Portalanza, 2019) 

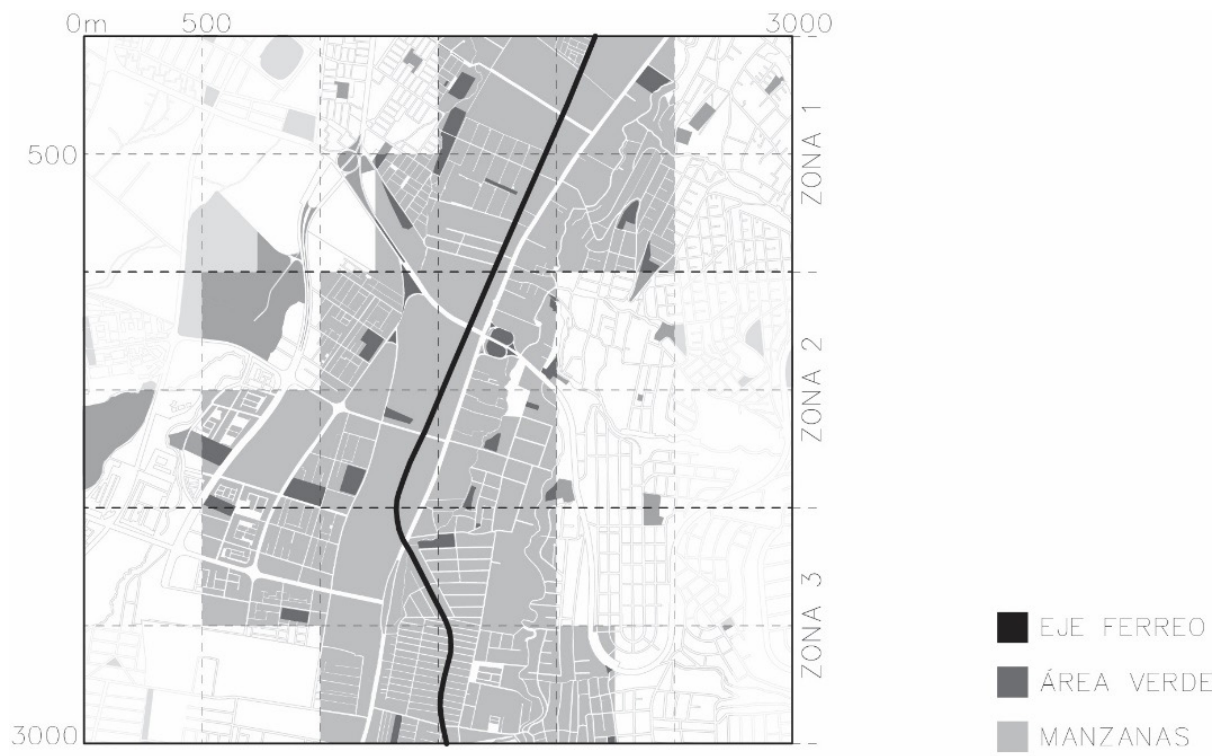

Fig. 3. Trama urbana y área verde. (Fuente: D. Silva, 2019)

formas de densificación actuales mediante tipologías arquitectónicas poco adecuadas no consolidan comunidades urbanamente activas; la morfología urbana tampoco está pensada de acuerdo con la proporción humana, los lotes donde se implantan las industrias si no logran adecuarse a las demandas de una ciudad compacta, llegarían a ser archipiélagos divisores de la urbe y el desarrollo de los pocos servicios y equipamientos de la zona no lograría mantenerla activa. Ante el déficit en el sector, muchos de los habitantes deben desplazarse diariamente al norte de la ciudad creando problemas de movilidad y dejando a un lado la idea de calidad de vida para las personas.

En busca de soluciones a la problemática se proponen estrategias para reactivar la zona postindustrial de Quitumbe. Todas las estrategias son ejemplificadas por medio de referentes o posturas heterogéneas.

\section{Posturas y estrategias}

Para afrontar la redefinición de la zona industrial y lograr una ciudad habitable se ha establecido las siguientes estrategias: por morfología urbana y por variantes tipológicas.
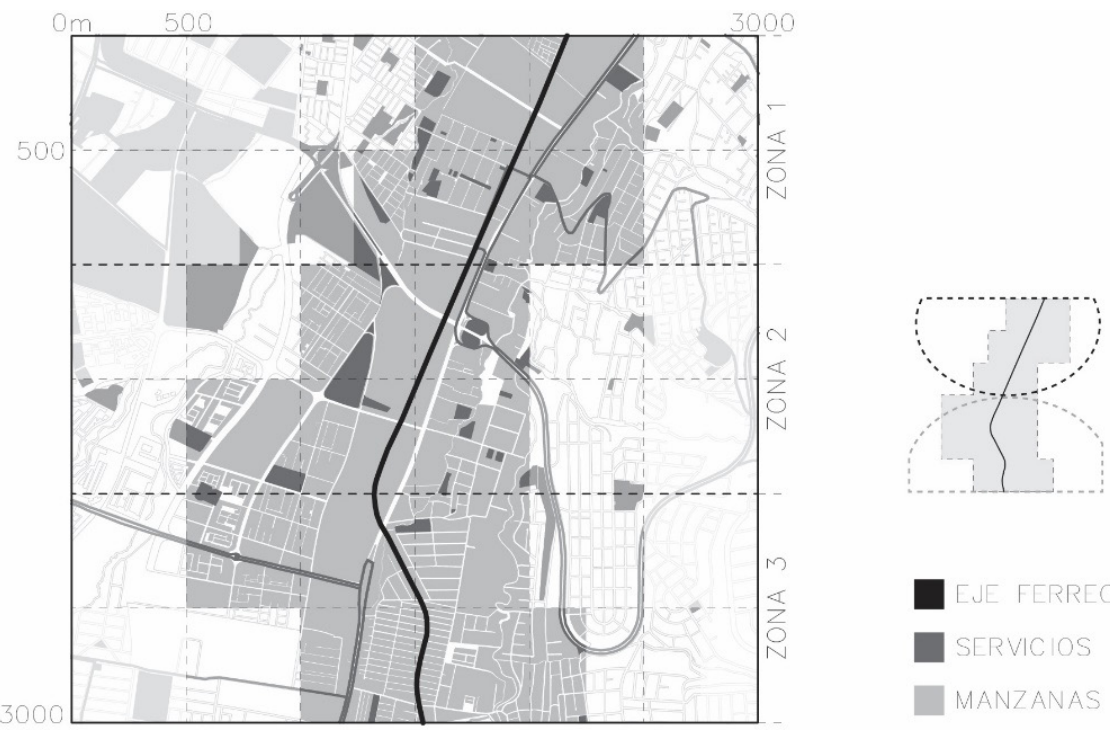

Fig. 4. Servicios y equipamientos. (Fuente: D. Silva, 2019) 


\section{Por morfología:}

Por medio de un análisis morfológico, podemos definir las preexistencias de la ciudad. Así, se puede considerar un proceso de racionalización de los datos objetivos que la ciudad nos brinda. En este caso, es un eje de transporte preexistente y una urbanización donde existen polígonos industriales con mayor preponderancia que elementos residenciales o de servicio. La primera opción ante una ocupación y posterior densificación de las amnesias urbanas producto de su cualidad postindustrial, articulada a un eje de movilidad, sería pensar en una condición de articulación lineal ${ }^{2}$. En el aspecto formal, la disposición plantea la consolidación del eje férreo, densificando la zona central del eje longitudinal de Quito, y así evitar la consolidación residencial de las laderas. Revisando el Plan Obus de Le Corbusier, y dejando de lado su condición visionaria y utópica, se puede plantear la propuesta de una infraestructura que acoja usos y servicios en un mismo objeto edilicio que a su vez articule movilidad, usos y permanencias. Esta postura nos hace recordar también al proyecto Nueva Babilonia de Constant.

El comportamiento urbano de Nueva Babilonia es lineal, una serie de recorridos que atraviesan el mundo. Nunca termina, puesto que la Tierra es redonda. Así, Constant ofrece una ciudad en donde sus ciudadanos se sientan apropiados de todo el planeta. Además, Constant (2009) señala lo siguiente en su manifiesto:

- "La propiedad colectiva del suelo y de los medios de producción y la racionalización de la producción de bienes de consumo favorecen la transformación de dicha energía en actividad creativa.

- La independencia respecto al lugar de trabajo tiene como consecuencia la independencia respecto al hábitat, al lugar de residencia. La movilidad de cada individuo en el espacio se ve incrementada."

El nuevo usuario ${ }^{3}$ ya no puede mantener una vida repetitiva. Sin caer en el utopismo situacionista de Nueva Babilonia, la estrategia busca rescatar su aporte en el replantear el modo de hábitat urbano. Adicionalmente cabe citar que se redefine, a través de una crítica, la condición privada de ciudad. Se podría plantear un eje lineal comunitario, social o desprivatizado, articulado a un ex eje férreo que reivindica y evoca su cualidad nómada. "La consolidación de la ciudad lineal es paulatina, crece con el nomadismo de sus habitantes. La infraestructura postindustrial será sustituida progresivamente ya que Nueva Babilonia se presenta como una red sobre el suelo" (Constant, 2009) Es importante que la propuesta de una condición morfológica incide directamente en el comportamiento utilitario, social e incluso político de sector de la ciudad. Esta característica nos da una idea de habitar los espacios de recorrido. Mediante esta deambulación, el ser humano se puede dar cuenta de los lugares inconscientes de la ciudad para asignarles nuevos significados. "Ver lo que no existe y hacer que surja algo de ello", (Careri, 2009). Cuando John Brinckerhoff dice que: "las carreteras ya no nos llevan solamente a unos lugares, sino que son lugares" ${ }^{\text {, nos }}$ está dando la pauta que algún día podrían ser

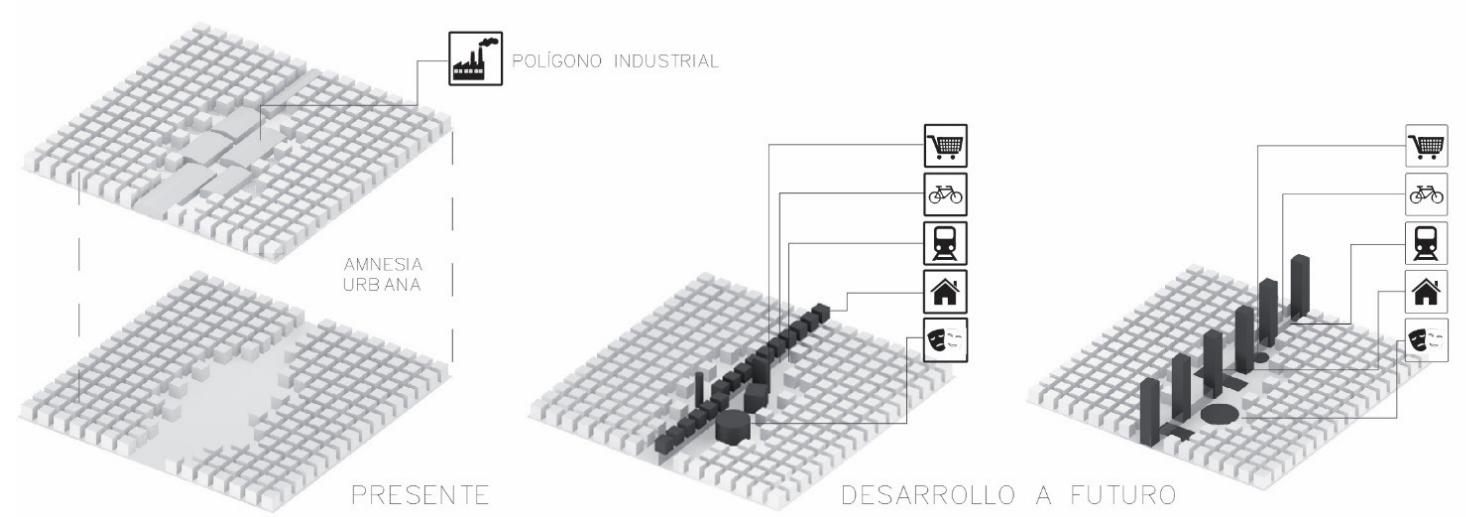

Fig. 5. Estrategia por morfología lineal. (Fuente: Autores, 2019) 
espacios habitables.

Como némesis de esta estrategia, la redefinición a través de tipologías verticales en dichas inserciones podría provocar una monotonía en planta baja, asemejándose a los centros financieros de Norteamérica. Sin embargo, una conformación lineal, no tiene porqué ser continua siempre. También la sucesión articulada de elementos fragmentados se acerca a la estrategia planteada (Fig. 5). La Ciudad Lineal de Magnitogorsk ${ }^{5}$ de Ivan Leonidov, por medio de la sucesión de fragmentos, redefine el habitar en una nueva manera de urbanismo. Además de ser una respuesta a la coyuntura de la formación de una nueva nación, la Unión Soviética.

\section{Por variantes tipológicas:}

A la estrategia planteada en el apartado anterior, se la puede complementar con las variaciones tipológicas de la misma. Por ejemplo, una organización lineal condicionada a un «palimpsesto de usos». (Fig. 6). Tal sería el caso del Puente Vecchio de Florencia, que es un vivo caso de arquitectura del recorrido. Que con el pasar del tiempo se ha convertido en un espacio habitable. Se presenta como una superposición de capas: el puente que es el elemento utilitario, luego un uso de permanencia superpuesto durante la Edad Media y finalmente un uso cultural y artístico que sería la Galería Ufizzi superpuesta durante el Renacimiento.

Otra postura es la negación del uso. Para ejemplificarla, se toma en cuenta el High Line Park en Nueva York. Este último es probablemente el que mayor semejanza tiene con el caso de estudio de Quitumbe. El proyecto no se establece como un ente densificador, pero

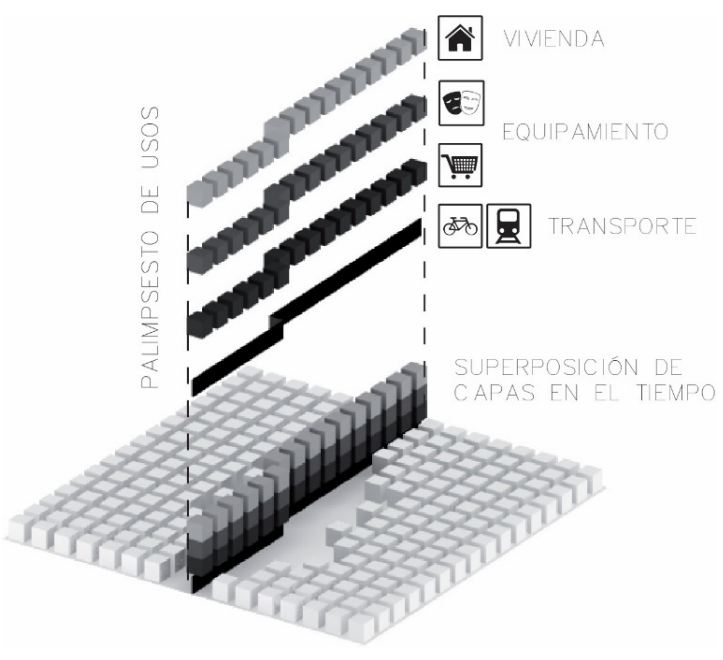

Fig. 6. Estrategia por palimpsesto de usos. (Fuente: Autores, 2019)

sí como un detonador para provocar a futuro una densidad poblacional más compacta. La razón es que su negación de uso industrial o de transporte pesado y la propuesta de su némesis, grandes ejes verdes, tratan con sutileza a lo saturado que puede ser la ciudad y así atraer nuevos usos o reconciliar otros preexistentes. En Nueva York, el High Line permite aglutinar nuevos usos residenciales, articulados a un gran eje ecológico que recibe actividades como deporte, ocio, cultura. (Fig. 7)

Como antítesis de la estrategia anterior en cuanto a usos, se propone un uso híbrido reivindicando su uso original. En este caso, su uso industrial, articulado a otros tales como vivienda, servicios, equipamientos, trasporte y ocio. Tal como hace más de un siglo lo habría imaginado Antonio Sant'Elia con sus dibujos visionarios de Citta Nuova (Fig. 8). En la misma temática de reivindicar el uso industrial, o bien, redefinir la postindustria con una industria
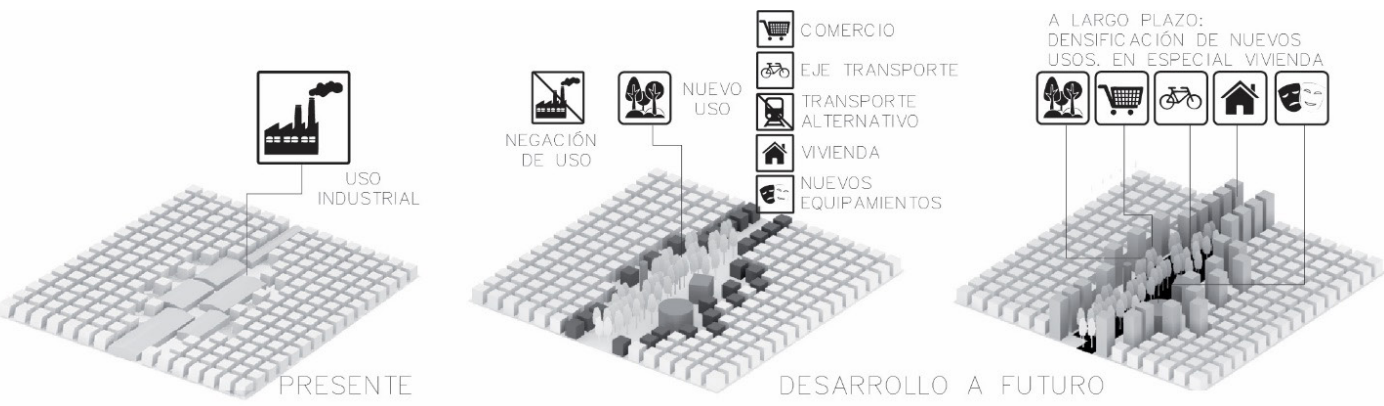

Fig. 7. Estrategia por negación de uso. (Fuente: Autores, 2019) 


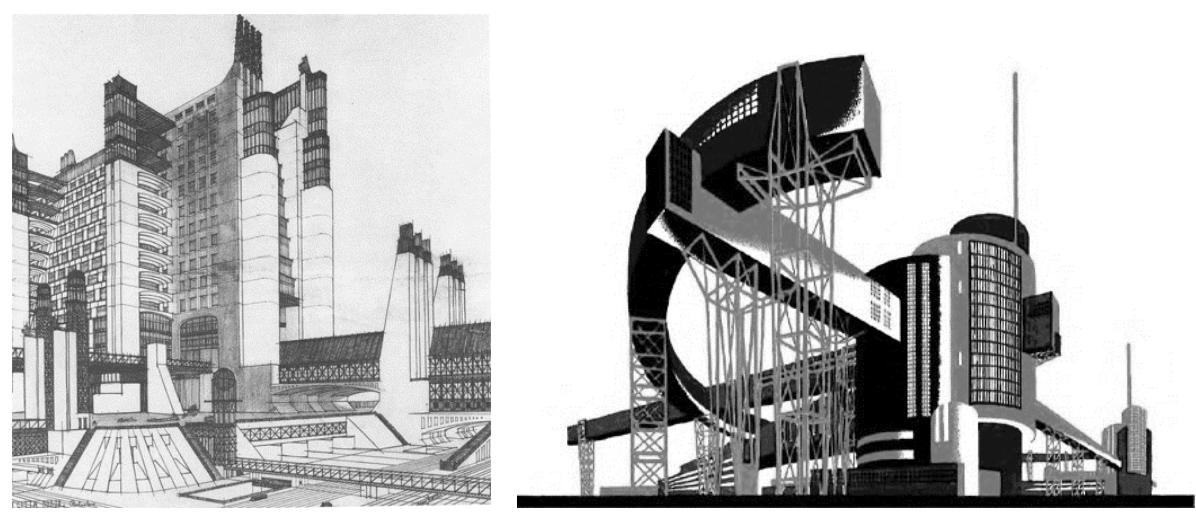

Fig. 8. Città Nuova. 1914. Obra de Antonio Sant'Elia. (Fuente: Dominio público)

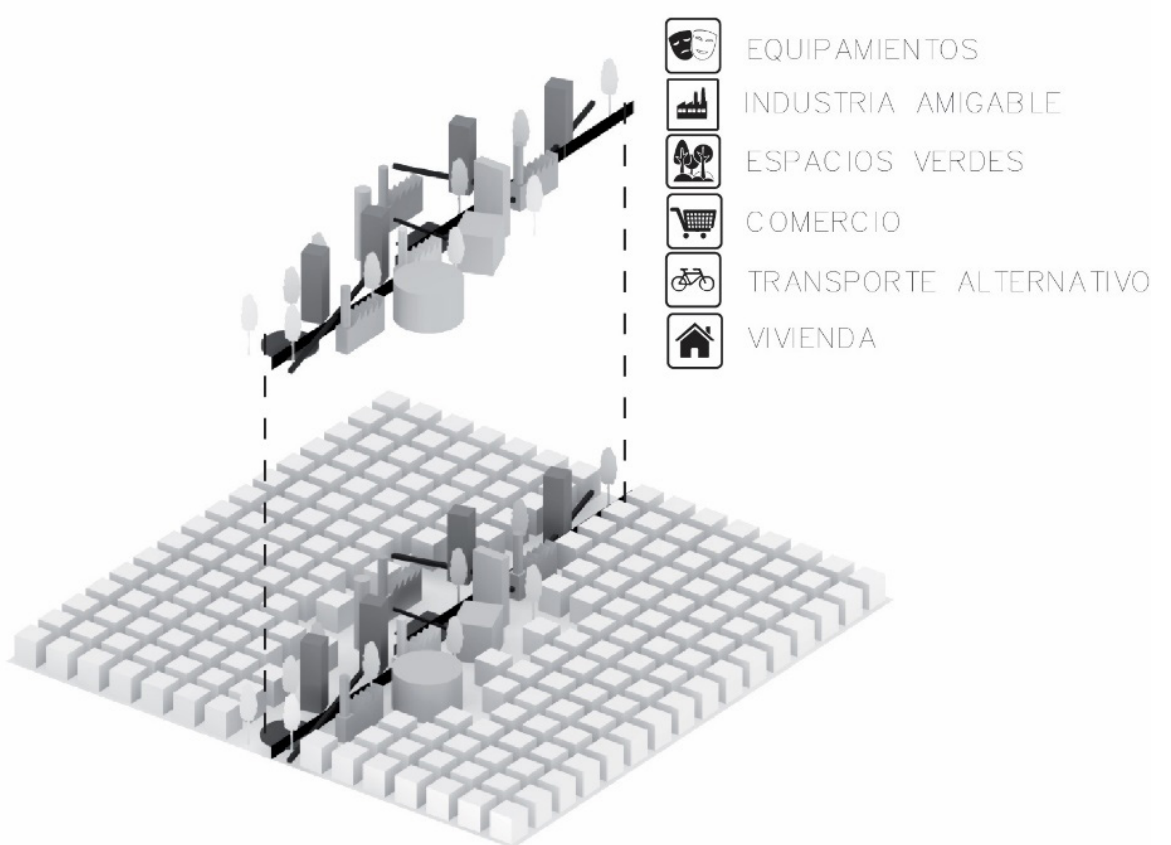

Fig. 9. Estrategia por reivindicación de uso original y mixticidad de usos. (Autores, 2019)

amigable, o renovada se puede ejemplificar la estrategia con las "fantasies architecturales" del constructivista ruso Iakov Chernikov. En dicho caso, la fábrica, busca ser monumentalizada y estetizada. Ya no sería un equipamiento residual sino uno cargado de simbolismo que se establecería como hito dentro de la ciudad. Y si de manera adicional se inserta lo verde, se puede lograr una industria amigable + vivienda + servicios + equipamiento + parque postindustrial en un solo eje articulador entre norte y sur, además de herramienta para lograr un Quito más compacto. (Fig. 9).

\section{Conclusiones}

Los datos arrojados por el análisis en cuanto a la densificación actual del sector, nos brinda un panorama claro de las políticas actuales de uso de suelo en la ciudad, si bien los resultados globales por sector atribuyen una densidad poblacional dentro de los márgenes establecidos por los planes urbanos propuestos, se evidencia una clara desproporción a su interior, datos cuantitativos desvirtúan de manera evidente la calidad de vida que se obtiene a partir de estas soluciones propias del siglo pasado.

El alarmante déficit de área verde expuesto en el estudio del sector puede ser revertido con estrategias de reutilización y fragmentación. Las actuales instalaciones del eje férreo y su infraestructura a lo largo del eje pueden aportar espacios de encuentro, la inclusión de nuevos usos de suelo a lo largo de la vía puede reactivar 
los actuales barrios dormitorio.

Los grandes polígonos olvidados en las centralidades del sector deben ser fragmentados, de tal manera que mantenga su carga histórica, resguardando la memoria de los usos pasados, pero a la vez liberar la trama urbana permitiendo la inclusión de equipamientos y servicios que logren consolidar barrios autónomos priorizando de esta manera la calidad de vida de sus "habitantes".

Los polígonos industriales no son incluyentes. Al mostrarse como una barrera en el eje este-oeste de Quito, provoca una ruptura en la morfología que no reconoce la dinámica de la ciudad moderna, ni la proximidad que debe existir entre el usuario y la ciudad, es necesario plantear una solución formal en cuanto a la estructuración de dichos polígonos, la inclusión de servicios, área verde y equipamientos que garanticen la calidad de vida suturando mediante una postura urbana.

Este estudio nos permite ver la importancia que el campo académico debe tener al momento de formular nuevas estrategias de planificación urbana y no cometer los mismos errores del pasado.

\section{Notas}

1 La infraestructura de un medio de transporte implica un recorrido. Por tal razón el desplazamiento encajaría perfectamente dentro de una condición morfológica lineal. Cabe recordar también que una morfología lineal también es respuesta al crecimiento longitudinal de Quito.

2 Apología al «neo-babilonio» que Constant lo define para su ciudad.

3 Careri (2009) lo cita de: John Brinckerhoff Jackson, Discovering the vernacular Landscape, Yale University Press, New Haven/Londres 1984.

4 En Frampton, Kenneth. 2009. Historia crítica de la arquitectura moderna se explica el plan de Ciudad Lineal de Magnitogorsk hecho por Leonidov en 1930. Para profundizar en dicho plan urbano se recomienda ver: Gozak, Andrei; Leonidov, Andre. 1988. Ivan Leonidov: the complete works. Academy Editions.

\section{Referencias}

Achig, Lucas. 1983. El proceso urbano de Quito. Quito: Tercer Mundo.

Aguilar, Paul; Bustos, Guillermo; Goetschel, Ana; Kigman, Eduardo; Luna, Milton; Ospina, Pablo; Perez, Juan; Valarezo, Ramón; Soasti, Guadalupe y Terán, Rosemarie. 1992. Enfoques y estudios históricos Quito a través de la Historia. Quito: TRAMA

Careri, Francesco. 2009. Walkscapes: el andar como práctica estética. Barcelona: Editorial Gustavo Gili.

Carrión, Fernando y Erazo Espinosa, Jaime. 2012 "La forma urbana de Quito: una historia de centros y periferias". Bulletin de l'Institut français d'études andines, no 41 (3), p. 503-522.

Cooke, Catherine. 1984. Chernikov Fantasy and Construction: Iakov Chernikhov's Approach to Architectural Design. Architectural Design.

Constant. 2009. La Nueva Babilonia. Barcelona: Editorial Gustavo Gili

Del Pozo, Paz Benito. 2004 "Discursos, propuestas y acciones sobre la ciudad postindustrial." En Anales de geografía de la Universidad Complutense. Servicio de Publicaciones,. p. 9-29.

Frampton, Kenneth. 2009. Historia crítica de la arquitectura moderna. Barcelona: Editorial Gustavo Gili.

Gutiérrez Juárez, Eduardo. 2013. "Equipamientos culturales como factor de cohesión urbana dentro de los procesos de regeneración en la ciudad. El caso de La Filmoteca de Cataluña en el barrio del Raval, Barcelona."

Gozak, Andrei; Leonidov, Andre. 1988. Ivan Leonidov: the complete works. Academy Editions.

Instituto Metropolitano de Planificación Urbana, I.M.P.U. 2018. Visión de Quito 2040 y su Nuevo Modelo de Ciudad. Quito: IMPU

Ortiz Crespo, Alfonso; Abram, Matthías; Segovia Nájera, José. 2007. Damero. Quito: FONSAL.

PricewaterhouseCoopers, PwC. 2012. Municipio de Quito Resultados de Estudio de Mercado - Prefactibilidad Parque 
Industrial Itulcachi. Quito: $\mathrm{PwC}$

Sabati, Francisco. 2006 La segregación social

del espacio en las ciudades de América

Latina. Inter-American Development Bank. 